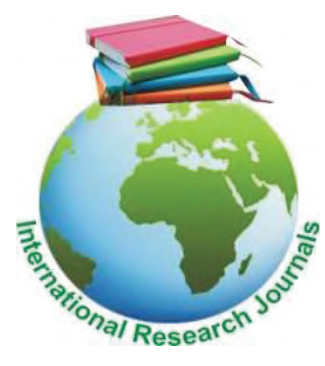

Disease diagnosis using an advanced distance measure for Intuitionistic Fuzzy Sets method Vol. 7(2) pp 029-042, September, 2018

DOI: http:/dx.doi.org/10.14303/irjm.2018.021

Available online http://www.interesjournals.org/IRJM

Copyright (C2018 International Research Journals

Full Length Research Paper

\title{
Disease diagnosis using an advanced distance measure for Intuitionistic Fuzzy Sets
}

\author{
Pranjal Talukdar, Palash Dutta* \\ Department of Mathematics, Dibrugarh University, Dibrugarh, Assam, India- 786004 \\ *Corresponding E-mail: palash.dtt@gmail.com
}

\begin{abstract}
In the application of intuitionistic fuzzy sets(IFSs), distance measures play a very important role in decision science. Though different distance measures of IFSs are developed with various aspects, many of them do not satisfy the axioms of distance measure or encounter some counterintuitive cases. To fill up the deficiency it is always useful to define novel distance measures, which motivates us towards the development of new distance measure. This paper presents a new method for distance measure between IFSs. For the efficiency and validity of the proposed distance measure a comparitive study is carried out with the numerical examples and also the distance measure is applied in a multi criteria decision making process. Finaly, two medical diagnosis problems are discudssed under this setting.
\end{abstract}

Keywords: Multi criteria decision making, distance measure, intuitionistic fuzzy sets, medical diagnosis.

\section{INTRODUCTION}

In many of real world situations, usually decision makers are confronted with multiple criteria to be considered before any decision can be made. In Decision science, one method which has a great importance in the field of research is TOPSIS. Distance measure is one of the most integral parts of this method. It was developed by Hwang and Yoon (Hwang et al., 1981). Multi criteria decision making process provides the best alternative among a set of alternatives in the presence of different criteria of the alternatives. Crisp data are not always adequate to model in many real life situations where as fuzzy set theory is more suitable to handle such type of situation. Further, Atanassov (Atanassov, 1986) developed the theory of Intuitionistic fuzzy set (IFS), a generalised concept of fuzzy set theory (FST). In FST, to each element of the universe of discourse a degree of membership between 0 and 1 is assigned and the degree of non membership is considered as complement to the membership degree. On the other hand, IFS does not imply that the non membership degree is always the complement of the membership degree. Instead, it characterised some hesitation degree between membership and non membership degrees. That is why, IFSs is more suitable to handle uncertainty than FST. Now a days, IFS theory becomes more popular for the uncertainty modelling problem and applied in a wide range of areas, such as, decision making, medical diagnosis (de et al., 2001, Szmit et al., 2005), fuzzy optimization, pattern recognition (Hung et al., 2004, Li et al., 2002, Li et al., 2007, Liang et al., 2003, Mitchell et al., 2003, Vlachos), logic programming (Atanassov et al., 1990), Distance measures, Divergence measures and similarity measures (Chen et al., 1994, Chen et al., 2016, Deng et al., 2015, Du et al., 2015, Beliakov et al., 2014, Zhang et al., 2014, Xu, 2017, Du et al., 2015, Hatzimichailidis et al., 2012, Ngan et al., 2018) are the important content in IFSs. Szmidt and Kacprzyk (Szmidt et al., 2000) proposed four distance measures of IFSs, which were based on the geometric interpretation of IFSs. Later, Grzegorzewski (Grzegorzewski et al., 2004), Szmidt and Kacprzyk (Szmidt et al., 2004) modified these distance measures. Further, Wang and Xin (Wang et al., 2005, Park et al., 2009) developed several distance and similarity measures of IFS (Yang et al., 2012). Singh and Garg (Singh et al., 2016) developed distance measures between the type-2 IFSs. Recently, Garg and 
Rani (Rani et al., 2017),Garg and Kumar (Garge et al., 2018, Garge et al., 2018 Garg et al., 2016, Garge et al., 2017), Garg and Arora have proposed distance measures of IFSs (Garg et al., 2017).

This paper presents a novel distance measure of IFSs. To show the validity, efficiency and applicability of the proposed distance measure a comparative study with numerical examples and two medical diagnosis problems are carried out through a multi critera decision making methodology. The detail work has been shortened as follows. Preliminaries starts with some relevant preliminary definitions. In propose distance measure between IFSs, a novel distance measure is proposed and numerical analysis has been done. Application of the proposed distance measure in Multi criteria decision making discusses the multi criteria decision making methodology by using the proposed distance measure. Two case studies of medical diagnosis have been studied through the methodology in Case study. Results and discussion are presented in Results and Discussion respectively. Finally, a concrete conclusion has been drawn in conclusion.

\section{PRELIMINARIES}

In this section, some basic concepts and necessary backgrounds of FST, IFSs are reviewed (Zadeh, 1965, Dutta et al., 2018).

\section{Fuzzy Set}

Fuzzy set is a set in which every element has degree of membership of belonging in it. Mathematically, let X be a universal set. Then the fuzzy subset $A$ of $X$ is defined by its membership function $\mu_{A} ; X \rightarrow[0,1]$, which assign a real number $\mu_{A}(x)$ in the interval $[0,1]$, to each element $x \in A$, where the value of $\mu_{A}(x)$ at $\mathrm{x}$ shows the grade of membership of $\mathrm{x}$ in A. i.e., $A=\left\{\left\langle x_{i}, \mu_{A}\left(x_{i}\right)\right\rangle: x_{i} \in X\right\}$.

\section{Intuitionistic Fuzzy Set}

A Intuitionistic fuzzy set $\mathrm{A}$ on a universe of discourse $\mathrm{X}$ is of the form $A=\left\{\left(x, \mu_{A}(x), v_{A}(x) ; x \in X\right)\right\}$, Where $\mu_{A}(x) \in[0,1]$ is called the "degree of membership of $x$ in A", $v_{A}(x) \in[0,1]$ is called the "degree of nonmembership of $\mathrm{x}$ in $\mathrm{A}$ ", and and $v_{A}(x)$ satisfy the condition that $0 \leq \mu_{A}(x)+\mu_{A}(x) \leq 1$. The amount $\pi_{A}(x)=1-\mu_{A}(x)-v_{A}(x)$ is called hesitancy of $\mathrm{x}$ which is reflection of lack of commitment or uncertainty associated with the membership or non-membership or both in $\mathrm{A}$.

\section{Metric}

Let $\mathrm{X}$ be a nonempty set and $\mathrm{A}, \mathrm{B}$ and $\mathrm{C}$ are IFSs on $\mathrm{X}$. Then the function is a metric (distance) if it satisfies the following axioms:

D1. $0 \leq d(A, B) \leq 1$

D2. $d(A, B)=0 \Leftrightarrow A=B$

D3. $d(A, B)=d(B, A)$

$D 4$. if $\mathrm{A} \subseteq \mathrm{B} \subseteq \mathrm{C}$, then $d(A, C) \geq d(A, B)$ and $d(A, C) \geq d(B, C)$

\section{Distance Measure Between IFSs}

Atanassov (Atanassov, 1999) suggested a direct generalization of the above distances for IFSs. For any two IFSs $A=\left\{\left(x, \mu_{A}(x), v_{A}(x): x \in X\right)\right\}$

$$
B=\left\{\left(x, \mu_{B}(x), v_{B}(x): x \in X\right)\right\} \text { on } \mathrm{X} \text {. }
$$

The Hamming distance $d_{H}(A, B)$ :

$d_{H}(A, B)=\frac{1}{2} \sum_{i=1}^{n}\left[\left|\mu_{A}\left(x_{i}\right)-\mu_{B}\left(x_{i}\right)\right|+\left|v_{A}\left(x_{i}\right)-v_{B}\left(x_{i}\right)\right|\right]$

The normalised Hamming distance $d_{n H}(A, B)$ :

$d_{n H}(A, B)=\frac{1}{2 n} \sum_{i=1}^{n}\left[\left|\mu_{A}\left(x_{i}\right)-\mu_{B}\left(x_{i}\right)\right|+\left|v_{A}\left(x_{i}\right)-v_{B}\left(x_{i}\right)\right|\right]$

The Euclidean distance $d_{e}(A, B)$ :

$d_{e}(A, B)=\sqrt{\frac{1}{2} \sum_{i=1}^{n}\left[\left(\mu_{A}\left(x_{i}\right)-\mu_{B}\left(x_{i}\right)\right)^{2}+\left(v_{A}\left(x_{i}\right)-v_{B}\left(x_{i}\right)\right)^{2}\right]}$

The normalised Euclidean distance $d_{n e}(A, B)$ :

$d_{n e}(A, B)=\sqrt{\frac{1}{2 n} \sum_{i=1}^{n}\left(\mu_{A}\left(x_{i}\right)-\mu_{B}\left(x_{i}\right)\right)^{2}+\left(v_{A}\left(x_{i}\right)-v_{B}\left(x_{i}\right)\right)^{2}}$

Wang and Xin proposed approach

$$
\begin{aligned}
d_{W}(A, B)=\frac{1}{n} \sum_{i=1}^{n}\left[\frac{\left|\mu_{A}\left(x_{i}\right)-\mu_{B}\left(x_{i}\right)\right|+\left|v_{A}\left(x_{i}\right)-v_{B}\left(x_{i}\right)\right|}{4}\right. \\
\left.+\frac{\max \left\{\left|\mu_{A}\left(x_{i}\right)-\mu_{B}\left(x_{i}\right)\right|,\left|v_{A}\left(x_{i}\right)-v_{B}\left(x_{i}\right)\right|\right\}}{2}\right]
\end{aligned}
$$

Szmidt and Kacprzyk further modified these distances for IFSs by considering the three parameters of IFS (Szmidt et al., 2000, Szmidt et al., 2004): degree of membership $\mu_{A}(x)$, degree of non-membership $v_{A}\left(x_{i}\right)$ and degree of hesitancy $\pi_{A}\left(x_{i}\right)$ given by: 


$$
\begin{aligned}
& d^{I}(A, B)=\frac{1}{2} \sum_{i=1}^{n}\left[\left|\mu_{A}\left(x_{i}\right)-\mu_{B}\left(x_{i}\right)\right|+\left|v_{A}\left(x_{i}\right)-v_{A}\left(x_{i}\right)\right|+\left|\pi_{A}\left(x_{i}\right)-\pi_{B}\left(x_{i}\right)\right|\right] \\
& d^{I I}(A, B)=\frac{1}{2 n} \sum_{i=1}^{n}\left[\left|\mu_{A}\left(x_{i}\right)-\mu_{B}\left(x_{i}\right)\right|+\left|v_{A}\left(x_{i}\right)-v_{B}\left(x_{i}\right)\right|+\left|\pi_{A}\left(x_{i}\right)-\pi_{B}\left(x_{i}\right)\right|\right] \\
& d^{I I I}(A, B)=\sqrt{\frac{1}{2} \sum_{i=1}^{n}\left[\left(\mu_{A}\left(x_{i}\right)-\mu_{B}\left(x_{i}\right)\right)^{2}+\left(v_{A}\left(x_{i}\right)-v_{B}\left(x_{i}\right)\right)^{2}+\left(\pi_{A}\left(x_{i}\right)-\pi_{B}\left(x_{i}\right)\right)^{2}\right]} \\
& d^{I V}(A, B)=\sqrt{\frac{1}{2 n} \sum_{i=1}^{n}\left[\left(\mu_{A}\left(x_{i}\right)-\mu_{B}\left(x_{i}\right)\right)^{2}+\left(v_{A}\left(x_{i}\right)-v_{B}\left(x_{i}\right)\right)^{2}+\left(\pi_{A}\left(x_{i}\right)-\pi_{B}\left(x_{i}\right)\right)^{2}\right]}
\end{aligned}
$$

\section{Grzegorzewski's distance measure}

$$
d^{V I}(A, B)=\frac{1}{n} \sum_{i=1}^{n} \max \left\{\left|\mu_{A}\left(x_{i}\right)-\mu_{B}\left(x_{i}\right)\right|,\left|v_{A}\left(x_{i}\right)-v_{B}\left(x_{i}\right)\right|\right\}
$$

\section{Yang and Francisco's distance measure}

$d^{V I I}(A, B)=\frac{1}{n} \sum_{i=1}^{n} \max \left\{\left|\mu_{A}\left(x_{i}\right)-\mu_{B}\left(x_{i}\right)\right|,\left|v_{A}\left(x_{i}\right)-v_{B}\left(x_{i}\right)\right|,\left|\pi_{A}\left(x_{i}\right)-\pi_{B}\left(x_{i}\right)\right|\right\}$

\section{Jin Han Park's distance measure}

$d^{V I I I}=\frac{1}{4 n} \sum_{i=1}^{n}\left(\left|\mu_{A}\left(x_{i}\right)-\mu_{B}\left(x_{i}\right)\right|+\left|v_{A}\left(x_{i}\right)-v_{B}\left(x_{i}\right)\right|+\mid \pi_{A}\left(x_{i}-\pi_{B}\left(x_{i}\right)\right)+2 \max \left\{\begin{array}{l}\left|\mu_{A}\left(x_{i}\right)-\mu_{B}\left(x_{i}\right)\right|,\left|v_{A}\left(x_{i}\right)-v_{B}\left(x_{i}\right)\right| \\ || \pi_{A}\left(x_{i}\right)-\pi_{B}\left(x_{i}\right) \mid\end{array}\right\}\right.$

\section{Song's distance measure}

$$
d^{I X}(A, B)=1-\frac{1}{3 n} \sum_{i=1}^{n}\left(\begin{array}{l}
2 \sqrt{\mu_{A}\left(x_{i}\right) \mu_{B}\left(x_{i}\right)}+2 \sqrt{v_{A}\left(x_{i}\right) v_{B}\left(x_{i}\right)}+\sqrt{\pi_{A}\left(x_{i}\right) \pi_{B}\left(x_{i}\right)}+\sqrt{\left(1-\mu_{A}\left(x_{i}\right)\right)\left(1-\mu_{B}\left(x_{i}\right)\right)} \\
+\sqrt{\left(1-v_{A}\left(x_{i}\right)\right)\left(1-v_{B}\left(x_{i}\right)\right)}
\end{array}\right)
$$

Hatzimichailidis's distance measure

$$
\begin{gathered}
d_{T}\left(A, B ; \sigma_{T}\right)=\frac{\left\|\Pi\left(\mu_{A}\right)-\Pi\left(\mu_{B}\right)\right\|+\left\|\Pi\left(v_{A}\right)-\Pi\left(v_{B}\right)\right\|}{2 n}, \text { where } \sigma_{T}(a, b)=\frac{}{a \vee b} \\
b \\
d_{R}\left(A, B ; \sigma_{R}\right)=\frac{\left\|\Pi\left(\mu_{A}\right)-\Pi\left(\mu_{B}\right)\right\|+\left\|\Pi\left(v_{A}\right)-\Pi\left(v_{B}\right)\right\|}{2 n}, \text { where } \sigma_{R}(a, b)=1-a+a b
\end{gathered}
$$

$d_{L}\left(A, B ; \sigma_{L}\right)=\frac{\left\|\Pi\left(\mu_{A}\right)-\Pi\left(\mu_{B}\right)\right\|+\left\|\Pi\left(v_{A}\right)-\Pi\left(v_{B}\right)\right\|}{2 n}, \quad$ where $\sigma_{L}(a, b)=\min (1,1-a+a b)$ 
4 Int. Res. J. Microbiol.

$d_{K D}\left(A, B ; \sigma_{K D}\right)=\frac{\left\|\Pi\left(\mu_{A}\right)-\Pi\left(\mu_{B}\right)\right\|+\left\|\Pi\left(v_{A}\right)-\Pi\left(v_{B}\right)\right\|}{2 n}$,

where $\sigma_{K D}(a, b)=\max (1-a, b)$

$d_{M}\left(A, B ; \sigma_{M}\right)=\frac{\left\|\Pi\left(\mu_{A}\right)-\Pi\left(\mu_{B}\right)\right\|+\left\|\Pi\left(v_{A}\right)-\Pi\left(v_{B}\right)\right\|}{2 n}$,

where $\sigma_{M}(a, b)=\max (a, b)$

$d_{L A}\left(A, B ; \sigma_{L A}\right)=\frac{\left\|\Pi\left(\mu_{A}\right)-\Pi\left(\mu_{B}\right)\right\|+\left\|\Pi\left(v_{A}\right)-\Pi\left(v_{B}\right)\right\|}{2 n}$,

where $\sigma_{L A}(a, b)=a b$

$d_{G}\left(A, B ; \sigma_{G}\right)=\frac{\left\|\Pi\left(\mu_{A}\right)-\Pi\left(\mu_{B}\right)\right\|+\left\|\Pi\left(v_{A}\right)-\Pi\left(v_{B}\right)\right\|,}{2 n}$,

where $\sigma_{G}(a, b)=1$ for $a \leq b$, for $a>b$

Minxia Luo and Ruirui Zhao's distance measure

$d_{f}(A, B ; f)=\frac{\left\|\Pi\left(\mu_{A}-\right) \Pi\left(\mu_{B}\right)\right\|+\left\|\Pi\left(v_{A}\right)-\Pi\left(v_{B}\right)\right\|+\| \Pi\left(\pi_{A}\right)-\Pi\left(\pi_{B}\right)}{2 n}$,

$$
\|\| \Pi \|=\sqrt{\lambda_{\max }}
$$

$\lambda$ is the largest non negative eigenvalue of positive definite Hermitian matrix $\prod^{T} \Pi$

\section{PROPOSE DISTANCE MEASURE BETWEEN IFSS}

In this section we propose new distance measure for IFSs defined on universe of discourse $X$ by taking into account all the three parameters: the degree of membership $\mu(x)$, the degree of non-membership $v(x)$ and concept of hesitancy degree $\pi(x)$, we define the distance measure on IFSs as follows. For any two IFSs

$A=\left\{\left(x, \mu_{A}(x), v_{A}(x): x \in X\right)\right\}$

$B=\left\{\left(x, \mu_{B}(x), v_{B}(x): x \in X\right)\right\}$ defined on universe of discourse $X$. Then we have

$d_{p p}(A, B)=\frac{1}{2 n e}\left[\sum_{i=1}^{n}\left[\begin{array}{r}\max \left\{\mu_{A}\left(x_{i}\right), \mu_{B}\left(x_{i}\right)\right\}_{1} \\ \left|\mu_{A}\left(x_{i}\right)-\mu_{A}\left(x_{i}\right)\right| \\ +\left|\pi_{A}\left(x_{i}\right)-\pi_{A}\left(x_{i}\right)\right|\end{array}\right.\right.$

$$
\left.\left.+e^{\max \left\{v_{A}\left(x_{i}\right), v_{B}\left(x_{i}\right)\right\}}\left|v_{A}\left(x_{i}\right)-v_{A}\left(x_{i}\right)\right|\right)\right]
$$

\section{Theorem}

$d_{p p}(A, B)$ is the degree of distance between two IFSs $\mathrm{A}$ and $\mathrm{B}$ in $X=\left\{x_{1}, x_{2}, \ldots \ldots \ldots \ldots . . ., x_{n}\right\}$.
Proof

Let $\quad A=\left\{\left(x, \mu_{A}(x), v_{A}(x): x \in X\right)\right\} \quad$ and $B=\left\{\left(x, \mu_{B}(x), v_{B}(x): x \in X\right)\right\}$ be two IFSs.Obviously, $d_{p p}(A, B)$ satisfies the axioms $D 1$. of definition 2.3. $D 2$. If $A=B$ then $\mu_{A}\left(x_{i}\right)=\mu_{B}\left(x_{i}\right)$ and $v_{A}\left(x_{i}\right)=v_{B}\left(x_{i}\right)$ then $d_{p p}(A, B)=0$

Conversely, if $d_{p p}(A, B)=0$ Then $\mathrm{A}=\mathrm{B}$.Therefore, $d_{p p}(A, B)=0 \Leftrightarrow A=B$

D3. Clearly, $d_{p p}(A, B)=d_{p p}(B, A)$

D4. For any IFSs $C=\left\{\left\langle x_{i}, \mu_{A}\left(x_{i}\right), v_{B}\left(x_{i}\right)\right\rangle: x_{i} \in X\right\}$ if $A \subseteq B \subseteq C$ then we have, $\mu_{A}\left(x_{i}\right) \leq \mu_{B}\left(x_{i}\right) \leq \mu_{C}\left(x_{i}\right)$ and $v_{C}\left(x_{i}\right) \leq v_{B}\left(x_{i}\right) \leq v_{A}\left(x_{i}\right)$

Thus,

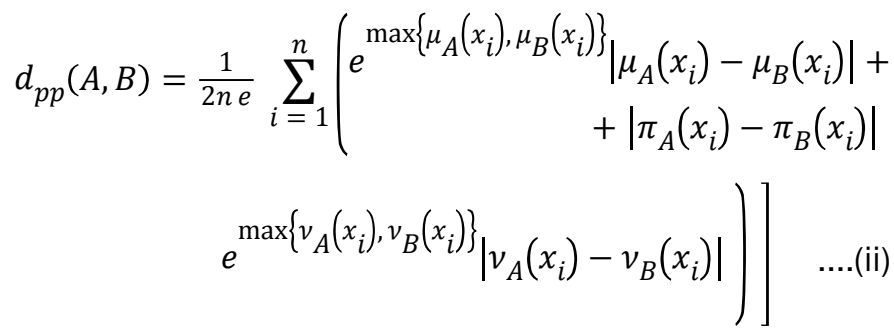
$d_{p p}(A, C)=\frac{1}{2 n e} \sum_{i=1}^{n}\left(\begin{array}{r}e^{\max \left\{\mu_{A}\left(x_{i}\right), \mu_{C}\left(x_{i}\right)\right\}}\left|\mu_{A}\left(x_{i}\right)-\mu_{C}\left(x_{i}\right)\right|+ \\ +\left|\pi_{A}\left(x_{i}\right)-\pi_{C}\left(x_{i}\right)\right|\end{array}\right.$ $\left.\left.e^{\max \left\{v_{A}\left(x_{i}\right), v_{C}\left(x_{i}\right)\right\}}\left|v_{A}\left(x_{i}\right)-v_{C}\left(x_{i}\right)\right|\right)\right]$

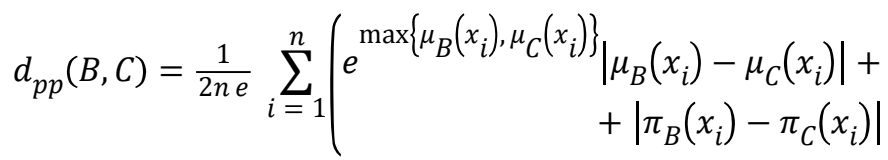
$\left.\left.e^{\max \left\{v_{B}\left(x_{i}\right), v_{C}\left(x_{i}\right)\right\}_{3}}\left|v_{B}\left(x_{i}\right)-v_{C}\left(x_{i}\right)\right|\right)\right]$

From (i), it is clear that

$\left|\mu_{A}\left(x_{i}\right)-\mu_{B}\left(x_{i}\right)\right| \leq\left|\mu_{A}\left(x_{i}\right)-\mu_{C}\left(x_{i}\right)\right|$

$\&\left|v_{A}\left(x_{i}\right)-v_{B}\left(x_{i}\right)\right| \leq\left|v_{A}\left(x_{i}\right)-v_{C}\left(x_{i}\right)\right|$

$\left|\mu_{B}\left(x_{i}\right)-\mu_{C}\left(x_{i}\right)\right| \leq\left|\mu_{A}\left(x_{i}\right)-\mu_{C}\left(x_{i}\right)\right|$

$\&\left|v_{B}\left(x_{i}\right)-v_{C}\left(x_{i}\right)\right| \leq\left|v_{A}\left(x_{i}\right)-v_{C}\left(x_{i}\right)\right|$

$\left|\pi_{B}\left(x_{i}\right)-\pi_{C}\left(x_{i}\right)\right| \leq\left|\pi_{A}\left(x_{i}\right)-\pi_{C}\left(x_{i}\right)\right|$

$\&\left|\pi_{B}\left(x_{i}\right)-\pi_{C}\left(x_{i}\right)\right| \leq\left|\pi_{A}\left(x_{i}\right)-\pi_{C}\left(x_{i}\right)\right|$ 
$e^{\max \left\{\mu_{A}\left(x_{i}\right), \mu_{B}\left(x_{i}\right)\right\}} \leq e^{\max \left\{\mu_{A}\left(x_{i}\right), \mu_{C}\left(x_{i}\right)\right\}}$

$\& e^{\max \left\{\mu_{B}\left(x_{i}\right), \mu_{C}\left(x_{i}\right)\right\}} \leq e^{\max \left\{\mu_{A}\left(x_{i}\right), \mu_{C}\left(x_{i}\right)\right\}}$

$e^{\max \left\{v_{A}\left(x_{i}\right), v_{B}\left(x_{i}\right)\right\}} \leq e^{\max \left\{v_{A}\left(x_{i}\right), v_{C}\left(x_{i}\right)\right\}}$

$\& e^{\max \left\{v_{B}\left(x_{i}\right), v_{C}\left(x_{i}\right)\right\}} \leq e^{\max \left\{v_{A}\left(x_{i}\right), v_{C}\left(x_{i}\right)\right\}}$

Therefore, from (ii), (iii) and (iv) it is seen that $d_{p p}(A, C) \geq d_{p p}(A, B)$ and $d_{p p}(A, C) \geq d_{p p}(B, C)$.
Thus, the above defined distance measure satisfies all the properties of metric as mentioned in the definition 2.3.

\section{NUMERICAL COMPARISON}

In this section, some numerical counterintuitive cases are considered to compare the different existing distance measure along with the proposed distance measure.

Table 1. Comparison of different distance measure with some counterintuitive examples of IFSs.

\begin{tabular}{|c|c|c|c|c|}
\hline $\begin{array}{l}\text { A } \\
\text { B }\end{array}$ & $\begin{array}{l}\{0.3,0.2,0.4,0.3\} \\
\{0.15,0.25,0.25,0.35\}\end{array}$ & $\begin{array}{l}\{0.3,0.2,0.4,0.3\} \\
\{0.16,0.26,0.26,0.36\}\end{array}$ & $\begin{array}{l}\{0.5,0.4,0.4,0.3\} \\
\{0.4,0.4,0.5,0.4\}\end{array}$ & $\begin{array}{l}\{0.5,0.4,0.4,0.3\} \\
\{0.6,0.3,0.3,0.2\}\end{array}$ \\
\hline $\mathrm{d}_{\mathrm{T}}$ & 0.05 & 0.05 & 0.11 & 0.1 \\
\hline$d_{R}$ & 0.05 & 0.05 & 0.05 & 0.05 \\
\hline $\mathrm{d}_{\mathrm{L}}$ & $5.55 \times 10^{-17}$ & $5.55 \times 10^{-17}$ & $5.55 \times 10^{-17}$ & $5.55 \times 10^{-17}$ \\
\hline$d_{M}$ & 0.1 & 0.1 & 0.07 & 0.09 \\
\hline$d_{L A}$ & 0.06 & 0.06 & 0.05 & 0.06 \\
\hline$d_{G}$ & 0.05 & 0.05 & 0.33 & 0.05 \\
\hline$d^{\prime V}$ & 0.13 & 0.12 & 0.14 & 0.14 \\
\hline $\mathrm{d}^{\mathrm{VII}}$ & 0.15 & 0.15 & 0.15 & 0.15 \\
\hline$d^{\text {VIII }}$ & 0.15 & 0.14 & 0.15 & 0.15 \\
\hline$d^{I X}$ & 0.01 & 0.01 & 0.01 & 0.03 \\
\hline$d_{f}$ & 0.2 & 0.19 & 0.14 & 0.18 \\
\hline$d_{p p}$ & 0.3807 & 0.3608 & 0.3894 & 0.4077 \\
\hline
\end{tabular}

In Table 1, most of the distance measures fail to reflect the exact distance between the IFSs A and B. The failure situations are highlighted with bold characters in Table 1. But our proposed distance measure can overcome such situation with a reasonable degree of distance measure for each pair of IFSs.

\section{APPLICATION OF THE PROPOSED DISTANCE MEASURE IN MULTI CRITERIA DECISION MAKING}

In general, multi criteria decision making problems include uncertain imprecise data and information. To show the validity and applicability in real world problem of the proposed distance measure, two multi criteria medical diagnosis problems are carried out to find the best alternatives among a set of alternatives.

\section{Methodology}

A decision making problem is a process to finding the best option among the set of feasible alternative.

Step1
Let us consider a set of $n$ alternatives $A 1, A 2, \ldots, A n$ and $\mathrm{C} 1, \mathrm{C} 2, \ldots, \mathrm{Cm}$ are the $\mathrm{m}$ criteria for each alternatives. The ratings $\tilde{x}_{i j}$ of each criteria $C_{j} ; \mathrm{j}=1,2, \ldots \ldots, \mathrm{m}$ for each alternatives $A_{i} ; \mathrm{i}=1,2, \ldots, \mathrm{n}$ are assign through IFSs. Thus, the relation of alternatives and criteria can be expressed in the matrix format as follows: $C_{1} C_{2} \quad \ldots \ldots . . . C_{m}$

$A_{1}$
$A_{2}$
$\vdots$
$A_{n}$$\left[\begin{array}{cccc}\tilde{x}_{11} & \tilde{x}_{12} & \ldots \ldots . . & \tilde{x}_{1 n} \\ \tilde{x}_{21} & \tilde{x}_{22} & \ldots \ldots . . & \tilde{x}_{2 n} \\ \tilde{x}_{m 1} & \tilde{x}_{m 2} & \ldots \ldots . . . & \tilde{x}_{m n}\end{array}\right]$

Step2

Assignments of weights of the different criteria for a certain group through IFSs.

The weights $\widetilde{w}_{j k} ; \mathrm{j}=1,2, \ldots, \mathrm{m} ; \mathrm{k}=1,2, \ldots, \mathrm{p}$ of different criteria $C_{j}$ for belonging to a certain group $D_{k}$ are 
obtained from the expert committee. The weights can be expressed in the matrix format as follows:

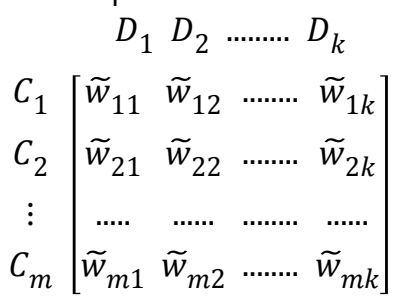

Step3

Calculate the distances between the ratings of the alternatives and the weights of the relevant criterion.

The relation between the alternatives and the different groups can be established in the matrix format as follows:

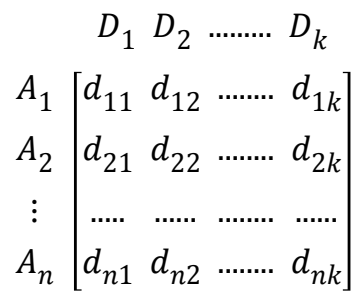

where, $d_{i k}$ is distance of the alternative $A_{i}$ from the weights of the criteria $C_{j}$ for belonging to a certain group.

Step4

Table 2. Patients-symptoms intuitionistic fuzzy relation.

\begin{tabular}{lllll}
\hline $\mathbf{P} \rightarrow \mathbf{S}$ & Temperature & Headache & Stomach pain & Cough \\
\hline Sankar & $(0.8,0.1)$ & $(0.6,0.1)$ & $(0.2,0.8)$ & $(0.6,0.1)$ \\
\hline Abhijit & $(0.0,0.8)$ & $(0.4,0.4)$ & $(0.6,0.1)$ & $(0.1,0.7)$ \\
\hline Amlan & $(0.8,0.1)$ & $(0.8,0.1)$ & $(0.0,0.6)$ & $(0.2,0.7)$ \\
\hline Aburba & $(0.6,0.1)$ & $(0.5,0.4)$ & $(0.3,0.4)$ & $(0.7,0.2)$ \\
\hline
\end{tabular}

Table 3. symptom-disease intuitionistic fuzzy relation.

\begin{tabular}{|c|c|c|c|c|c|}
\hline$S \rightarrow D$ & Viral Fever & Malaria & Typhoid & Stomach & Chest Problem \\
\hline Temperature & $(0.4,0.0)$ & $(0.7,0.0)$ & $(0.3,0.3)$ & $(0.1,0.7)$ & $(0.1,0.8)$ \\
\hline Stomachpain & $(0.1,0.7)$ & $(0.0,0.9)$ & $(0.2,0.7)$ & $(0.8,0.0)$ & $(0.2,0.8)$ \\
\hline Cough & $(0.4 .0 .3)$ & $(0.7,0.0)$ & $(0.2,0.6)$ & $(0.2,0.7)$ & $(0.2,0.8)$ \\
\hline Chestpain & $(0.1,0.7)$ & $(0.1,0.8)$ & $(0.1,0.9)$ & $(0.2,0.7)$ & $(0.8,0.1)$ \\
\hline
\end{tabular}

Now, evaluating the distance value using the proposed distance measure for the above data sets (Table 2 \& Table 3) the following Table 4 is constructed:

Table 4. Distance value and patient-disease intuitionistic fuzzy relation.

If the distance is less, it indicates that the alternative is more nearer to its relevant group. Therefore, rank the alternative according to the decreasing order of their distances.

\section{CASE STUDY}

\section{Case Study 1}

In this section, two hypothetical case studies have been carried out to perform medical diagnosis using the concept of IFSs based on the proposed distance measure. Here, it is proposed to take into account the three parameters characterization of IFSs: the membership degree, the non-membership degree and decision maker's hesitancy degree.

Let $P=\{$ Sankar, Abhijit, Amlan, Apurba $\}$ be the set of patients, $S=$ temperature, headache, stomach pain, cough, chest pain $\}$ be the set of symptoms, $D=\{$ viral fever, Malaria, typhoid, stomach problem, chest problem\} be the set of diseases. Our intention is to carry out the right decision for each patient $p_{i}, i=1,2,3,4$ from the set of symptoms $s_{j}, j=1,2,3,4,5$ for each disease $d_{k}, k=1,2,3,4,5$.

The patient-symptom intuitionistic fuzzy relation $P \rightarrow S$ and symptom-disease intuitionistic fuzzy relation $S \rightarrow D$ are given in Table 2 and Table 3 respectively. 


\begin{tabular}{llllll}
\hline $\mathbf{P} \rightarrow \mathbf{D}$ & Viral Fever & Malaria & Typhoid & Stomach & Chest Problem \\
\hline Sankar & 0.1770 & 0.1473 & 0.1869 & 0.3816 & 0.4168 \\
\hline Abhijit & 0.2725 & 0.3705 & 0.2078 & 0.0812 & 0.2985 \\
\hline Amlan & 0.2500 & 0.3046 & 0.2089 & 0.3530 & 0.4155 \\
\hline Apurba & 0.1716 & 0.1891 & 0.2441 & 0.2966 & 0.3785 \\
\hline
\end{tabular}

\section{Case Study 2}

Let there be four Patients $\mathrm{P}=\{$ Shyam, Soumendra, Jadov, Joydeep\} and the set of symptoms $S=$ \{Headache, Acidity, Burning Eyes, Back pain, Depression $\}$ Let the set of Disease be $D=\{$ Stress, Ulcer, Vision problem, Spinal problems, Blood pressure\}. The patients-symptoms intuitionistic fuzzy relation $P \rightarrow S$ and the symptoms-disease intuitionistic fuzzy relation $S \rightarrow D$ are shown in the Table 5 and Table 6 respectively. The patients-disease relation $P \rightarrow D$ is constructed in Table 7.

Table 5. Patients-symptoms intuitionistic fuzzy relation.

\begin{tabular}{cccccc}
\hline $\mathbf{P} \rightarrow \mathbf{S}$ & Headache & Acidity & Burning Eyes & Back Pain & Depression \\
\hline Shyam & $(0.9,0.1)$ & $(0.7,0.2)$ & $(0.2,0.8)$ & $(0.7,0.2)$ & $(0.2,0.7)$ \\
\hline Soumendra & $(0.0,0.7)$ & $(0.4,0.5)$ & $(0.6,0.2)$ & $(0.2,0.7)$ & $(0.1,0.2)$ \\
\hline Jadov & $(0.7,0.1)$ & $(0.7,0.1)$ & $(0.0,0.5)$ & $(0.1,0.7)$ & $(0.0,0.6)$ \\
\hline Joydeep & $(0.5,0.1)$ & $(0.4,0.3)$ & $(0.4,0.5)$ & $(0.8,0.2)$ & $(0.3,0.4)$ \\
\hline
\end{tabular}

Table 6. Symptom-disease intuitionistic fuzzy relation.

\begin{tabular}{|c|c|c|c|c|c|}
\hline $\mathbf{S} \rightarrow \mathbf{D}$ & Stress & Ulcer & Vision Problem & Spinal Problem & Blood Pressure \\
\hline Headache & $(0.3,0.0)$ & $(0.0,0.6)$ & $(0.2,0.2)$ & $(0.2,0.8)$ & $(0.2,0.8)$ \\
\hline Acidity & $(0.3,0.5)$ & $(0.2,0.6)$ & $(0.5,0.2)$ & $(0.1,0.5)$ & $(0.0,0.7)$ \\
\hline Burning Eyes & $(0.2,0.8)$ & $(0.0,0.8)$ & $(0.1,0.7)$ & $(0.7,0.0)$ & $(0.2,0.8)$ \\
\hline Back Pain & $(0.7,0.3)$ & $(0.5,0.0)$ & $(0.2,0.6)$ & $(0.1,0.7)$ & $(0.1,0.8)$ \\
\hline Depression & $(0.2,0.6)$ & $(0.1,0.8)$ & $(0.2,0.8)$ & $(0.2,0.7)$ & $(0.8,0.1)$ \\
\hline $\mathbf{P} \rightarrow \mathbf{D}$ & Stress & Ulcer & Vision Problem & Spinal Problem & Blood Pressure \\
\hline Shyam & 0.15534 & 0.2647 & 0.2115 & 0.393 & 0.404 \\
\hline Soumendra & 0.2939 & 0.2777 & 0.2496 & 0.1475 & 0.2521 \\
\hline Jadov & 0.2557 & 0.3482 & 0.1902 & 0.3451 & 0.3846 \\
\hline Joydeep & 0.1229 & 0.2507 & 0.208 & 0.3186 & 0.3558 \\
\hline
\end{tabular}

Table 7. distance value and patients-disease intuitionistic fuzzy relation.

\section{RESULTS}

The principle of minimum distance degree states that the lower distance degree of alternative signifies a proper diagnosis. The obtained results have been highlighted by bold character in Table 4 and in Table 7. From the Table 4 the proper diagnosis are Sankar suffers from Malaria, Ahbijit suffer from Stomach pain, Amlan suffers from Typhoid and Apurba suffers from
Viral fever, which coincides with the results (Pramanik et al., 2015, Szmidt et al., 2001, Wei et al., 2011, Luo et al., 2018) and from the Table 7 , Shyam suffers from stress, Soumendra suffers from spinal problems, Jadov suffers from vision problem and Joydeep suffers from stress. From numerical comparison, it has been observed that the proposed distance measure can overcome the counterintuitive cases whereas most of the existing distance measure failed to reflect the same. Thus, the obtained results in the above medical diagnosis problems by using the proposed distance 
measure can be recognised as more confident and improved results.

\section{DISCUSSION}

Various studies have been done so far in medical diagnosis using fuzzy set, interval valued fuzzy set, intuitionistic fuzzy, interval valued intuitionistic fuzzy set etc. It is seen that IFS gained more popularity in medical diagnosis because of its interesting concept of membership and non-membership degree. Different distance measures are developed and have applied in many different areas under IFSs environment but many of them fails to handle some critical situation (Numerical comparison). Therefore, the use of such distance measures may mislead some illogical results or may not evaluate the results properly. To obtain proper and logical results in various problems in different branches, the proposed distance measure can be implemented as a novel and efficient distance measure.

\section{CONCLUSION}

This paper attempts to devise a novel distance measure between IFSs to effectively resolve the shortcomings of the existing distance measures. The proposed distance measure considers all the three assignment, the hesitancy degree $\pi$, the membership degree $\mu$ and non-membership degree $v$ instead of taking only the membership degree $\mu$ and nonmembership degree $v$. The validity and efficiency of the proposed method has been shown by studying a comparative analysis through numerical illustrations and medical decision making analysis via the proposed approach. In the future work, the presented approach has been extended to Pythagorean fuzzy sets and some other uncertain environment (Garg et al., 2018, Garg, 2018, Song et al., 2017).

\section{REFERENCES}

Atanassov K (1999). Intuitionistic Fuzzy Sets: Theory and Applications. Physica-Verlag, Wyrzburg.

Atanassov K, Gargov G (1990). Intuitionistic fuzzy logic. CR Acad. Bulg. Soc. 43:9-12.

Attanassov KT (1986). Intuitionistic fuzzy sets. Fuzzy Sets and Systems. 20:87-96.

Beliakov G, Pagola M, Wilkin T (2014). Vector valued similarity measures for Atanassov's intuitionistic fuzzy sets. Information Sciences. 280:352-367.

Chen SM, Cheng SH, Lan TC (2016). A novel similarity measure between intuitionistic fuzzy sets based on the centroid points of transformed fuzzy numbers with applications to pattern recognition. Information Sciences. 27:343-344.
Chen SM, Tan JM (1994). Handling multi-criteria fuzzy decision making problems based on vague sets. Fuzzy Sets and Systems. 67:63-172.

De SK, Biswas P, Roy AR (2001). Application of intuitionistic fuzzy sets in medical diagnosis. Fuzzy Sets and Systems. 117:209-213.

Deng G, Jiang Y, Fu J (2015). Monotonic similarity measures between intuitionistic fuzzy sets and their relationship with entropy and inclusion measure. Information Sciences. 316:348-369.

Du WS, Hu BQ (2015). Aggregation distance measure and its induced similarity measure between intuitionistic fuzzy sets. Pattern Recognition Letters. 60:65-71.

Dutta P, Talukdar P (2018). A Novel Arithmetic Technique for Generalised Interval-Valued Triangular Intuitionistic Fuzzy Numbers and Its Application in Decision Making. The Open Cybernetics \& Systemics Journal. 12:72-120.

Garg H (2018). Generalized Pythagorean fuzzy geometric interactive aggregation operators using Einstein operations and their application to decision making. Journal of Experimental \& Theoretical Artificial Intelligence, Taylor \& Francis.

Garg H (2018). Linguistic Pythagorean fuzzy sets and its applications in multi attribute decision making process. International Journal of Intelligent Systems. 33:1234-1263.

Garg H, Arora R (2017). Distance and similarity measures for dual hesitant fuzzy soft sets and their applications in multi-criteria decision making problem. International Journal for Uncertainty Quantification. 7: $229-248$.

Garg H, Arora R (2018). Dual hesitant fuzzy soft aggregation operators and their application in decision making. Cognitive Computation, Springer.

Garg H, Kumar K (2016). TOPSIS method based on the connection number of set pair analysis under interval-valued intuitionistic fuzzy set environment. Computational \& Applied Mathematics, Springer. 37:1319-1329.

Garge H, Kumar K (2017). Connection number of set pair analysis based TOPSIS method on intuitionistic fuzzy sets and their application to decision making. Applied Intelligence. 48:2112-2119.

Garge H, Kumar K (2018). An advanced study on the similarity measures of intuitionistic fuzzy sets based on the set pair analysis theory and their application in decision making. Soft Computing, Springer. 22:4959-4970.

Garge H, Kumar K (2018). Distance measures for connection number sets based on set pair analysis and its applications to decision-making process. Applied Intelligence.

Grzegorzewski P (2004). Distances between intuitionistic fuzzy sets and/or interval-valued fuzzy 
sets based on the Hausdor metric. Fuzzy Sets and Systems. 148:319-328.

Hatzimichailidis AG, Papakostas GA, Kaburlasos VG (2012). A novel distance measure of intuitionistic fuzzy sets and its application to pattern recognition problems. International Journal of Intelligent Systems. 27:396-409.

Hung WL, Yang MS (2004). Similarity measures of intuitionistic fuzzy sets based on Hausdorff distance. Pattern Recognition Lett. 25: 1603-1611.

Hwang CL, Yoon K (1981). Multiple Attribute Decision Making Method and application. Heidelberg Verlag Berlin: Springer.

Li D, Cheng C (2002). New similarity measures of intuitionistic fuzzy sets and applications to pattern recognitions. Pattern Recognition Lett. 23:221- 225.

Li Y, Olson DL, Qin Z (2007). Similarity measures between intuitionistic fuzzy (vague) sets: A comparative analysis. Pattern Recognition Lett. 28:278- 285.

Liang Z, Shi P (2003). Similarity measures on intuitionistic fuzzy sets. Pattern Recognition Lett. 24:2687-2693.

Luo M, Zhao R (2018). A distance measure between intuitionistic fuzzy sets and its application in medical diagnosis. Artificial Intelligence In Medicine. 89:34-39.

Mitchell HB (2003). On the Dengfeng-Chuitian similarity measure and its application to pattern recognition. Pattern Recognition Lett. 24:3101-3104.

Ngan RT, Son LH, Cuong BC, Ali M (2018). H-max distance measure of intuitionistic fuzzy sets in decision making. Applied Soft Computing. 69:393-425.

Park JH, Lim KM, Kwun YC (2009). Distance measure between intuitionistic fuzzy sets

and its application to pattern recognition. Korean Institute of Intelligent Systems, 19:556-561.

Pramanik S, Mondal K (2015). Intuitionistic fuzzy similarity measure based on tangent function and its application to multi-attribute decision making. Glob J Adv Res. 2:464-71.

Rani D, Garg H (2017). Distance measures between the complex intuitionistic fuzzy sets and its applications to the decision-making process. International Journal for Uncertainty Quantification, 7:423-439.
Singh S, Garg H (2016). Distance measures between type-2 intuitionistic fuzzy sets and their application to multicriteria decision-making process. Appl. Intell. 46:788-799.

Song YF, Wang XD, Quan W, Huang W (2017). A new approach to construct similarity measure for intuitionistic fuzzy sets. Soft Comput, 1:1-14.

Szmidt E, Kacprzyk J (2000). Distances between intuitionistic fuzzy sets. Fuzzy Sets and Systems, 114:505-518.

Szmidt E, Kacprzyk J (2001). Intuitionistic fuzzy sets in intelligent data analysis for medical diagnosis. International conference on computational science. 113:263-71.

Szmidt E, Kacprzyk J (2004). A similarity measure for intuitionistic fuzzy sets and its application in supporting medical diagnostic reasoning. Artificial Intelligence and Soft Computing - ICAISC 2004. Lecture Notes in Computer Science. 3070:388-393.

Szmit E, Kacprzyk J (2005). A new concept of a similarity measure for intuitionistic fuzzy sets and its use in group decision making. LNCS. 3558:272-282.

Vlachos IK, Sergiadis GD (2007). Intuitionistic fuzzy information Applications to pattern recognition. Pattern RecognitionLett. 28:197-206.

Wang W, Xin X (2005). Distance measure between intuitionistic fuzzy sets. Pattern Recognition Letters. 26:2063-2069.

Wei CP, Wang P, Zhang YZ (2011). Entropy, similarity measure of interval-valued intuitionistic fuzzy sets and their applications. Inf Sci. 181:4273-86.

$\mathrm{Xu} \mathrm{C}$ (2017). Improvement of the distance between intuitionistic fuzzy sets and applications. Journal of Intelligent \& Fuzzy Systems. 33:1563-1575.

Yang Y, Chiclana F (2012). Consistency of 2D and 3D distances of intuitionistic fuzzy sets. Expert Systems with Applications, 39:8665-8670.

Zadeh LA (1965). Fuzzy sets. Inform. Control. 8:338-356.

Zhang Q, Xing H, Liu F, Ye J, Tang P (2014). Some new entropy measures for interval-valued intuitionistic fuzzy sets based on distances and their relationships with similarity and inclusion measures. Information Sciences. 283:55-69. 